Supporting Information

\title{
Unique Orientation of the Solid-Solid Interface at the Janus Particle Boundary Induced by Ionic Liquids
}

\author{
Ayuna Tsyrenova, ${ }^{\dagger}$ Muhammad Q. Farooq, ${ }^{\ddagger}$ Stephen M. Anthony, ${ }^{\S}$ Keyvan Mollaeian," \\ Yifan Li, ${ }^{\dagger}$ Fei Liu, ${ }^{\dagger}$ Kyle Miller, ${ }^{\dagger}$ Juan Ren,,$"$ Jared L. Anderson, ${ }^{\ddagger}$ Shan Jiang ${ }^{\dagger, \# *}$ \\ ${ }^{\dagger}$ Department of Materials Science and Engineering, Iowa State University, Ames, IA 50011, USA \\ ‡ Department of Chemistry, Iowa State University, Ames, IA 50011, USA \\ $\S$ Department of Computational Biology and Biophysics, Sandia National Laboratories, Albuquerque, NM, \\ 87123, USA \\ " Department of Mechanical Engineering, Iowa State University, Ames, IA 50011, USA \\ \# Division of Materials Science \& Engineering, Ames National Laboratory, Ames, IA 50011, USA \\ *E-mail: sjiang1@iastate.edu
}


Chemicals and reagents. 1-Octadecanelthiol (ODT), butanethiol, dodecanethiol, sodium dodecyl sulfate (SDS), and hexadecyltrimethylammonium bromide (CTAB) were purchased from Sigma Aldrich (USA). The reagents 1-methylimidazole (99\%), 1,2-dimethylimidazole (>98\%), 1-bromobutane (99\%), 1bromodecane (>98\%), acetonitrile (99.9\%) and diethyl ether (>98\%) were purchased from Millipore Sigma (St. Louis, MO, USA). Deuterated dimethyl sulfoxide (d6-DMSO) was obtained from Cambridge Isotope Laboratories (Andover, MA, USA). Deionized distilled water of 18.3 resistivity was used in all experiments.

Synthesis of ionic liquids. Firstly, $10 \mathrm{mmol}$ of alkylimidazole (1-methylimidazole or 1,2dimethylimidazole) were dissolved in $40 \mathrm{~mL}$ of acetonitrile in a round bottom flask. Then, $12 \mathrm{mmol}$ of haloalkane (1-bromobutane or 1-bromodecane) were added to the flask and the reaction mixture refluxed for 48 hours at $80^{\circ} \mathrm{C}$. Solvent was then removed by roto-evaporation and the product dissolved in deionized water. Purification was performed by washing the product several times with $5 \mathrm{~mL}$ aliquots of diethyl ether in a separation funnel. Deionized water was evaporated by roto-evaporation and all purified ILs were dried in vacuum oven for 24 hours at room temperature. All ILs were characterized by ${ }^{1} \mathrm{H}$ and ${ }^{13} \mathrm{C}$ NMR, all spectra are provided in Figure S2.

Fabrication of Janus particles. Amphiphilic Janus particles were fabricated using previously published method. ${ }^{12}$ Monolayers of silica particles of 3 um diameter (Tokuyama) were directly coated with 2-4 nm chromium adhesion layer and 20-40 nm Au top layer using e-beam evaporation machine Temescal. The Au side of the particles was rendered hydrophobic with a thiol self-assembled monolayer. After modification, Janus particles were dispersed in distilled water and used fresh for the assembly experiments.

Assembly procedure. Nunc ${ }^{\mathrm{TM}}$ Lab-Tek $^{\mathrm{TM}}$ 16-well chambered glass slides were used for the Janus particle self-assembly experiments. Dispersed particles were allowed to sediment onto chamber's bottom for no less than 12 hours. Due to gravity, a 2D monolayer of particles was formed above a flat substrate. Sample cells were sealed with a paraffin during the sedimentation process. Concentrated solutions of ionic liquid were added to the particles dispersion to reach $1 \mathrm{mM}, 2 \mathrm{mM}, 5 \mathrm{mM}$, or $10 \mathrm{mM}$ concentration in the chamber. Image analysis. Optical images were obtained with inverted optical microscope Leica DMi8 in a transmission mode. Particles tracking and orientation analysis was performed with a custom made MatLab code. For each condition, more than 1500 particles were analyzed. The location and orientation of each of the Janus particles was determined using the custom code developed in MatLab. For orientation analysis of particles in 2D plane, we followed the previously published procedure (Ref. 12 of the main text). Out-ofplane angle, theta, was determined as an angle between particle's axis in z-direction and a normal to a substrate. Theta angle was estimated based on a ratio of pixel intensities.

Quartz crystal microbalance. SRS QCM-200 device was used to measure the frequency change upon addition of ionic liquid. A flow cell set up was used to minimize the signal fluctuations. The QCM device 
was set up in a flow injection analysis mode. Analyte was injected into a flow cell using a 2-way injection valve at $50 \mathrm{ul} / \mathrm{min}$ flow rate. After each analyte injection a crystal was rinsed with DIW and frequency was equilibrated. All the solutions were degassed and stored at the same temperature.

AFM experiment. AFM force measurements were performed with Bruker BioScope Resolve AFM system (Santa Barbara, CA, USA), integrated with an inverted optical microscope (Olympus, IX73, Japan). A glass bead colloidal AFM probe (Novascan, IA, USA) with sphere radius of 2.5 um was used, and the spring constant of $0.046 \mathrm{~N} / \mathrm{m}$ was acquired using thermal tune approach. ${ }^{23}$ All force measurements were performed in contact mode in liquid at the rate of $0.1 \mathrm{~Hz}$ (i.e., $99.2 \mathrm{~nm} / \mathrm{s}$ ) and force threshold of $2.25 \mathrm{nN}$. For each experimental condition, the average value of probe-substrate rupture force was calculated on at least 10 force curves obtained from different locations on the substrate.
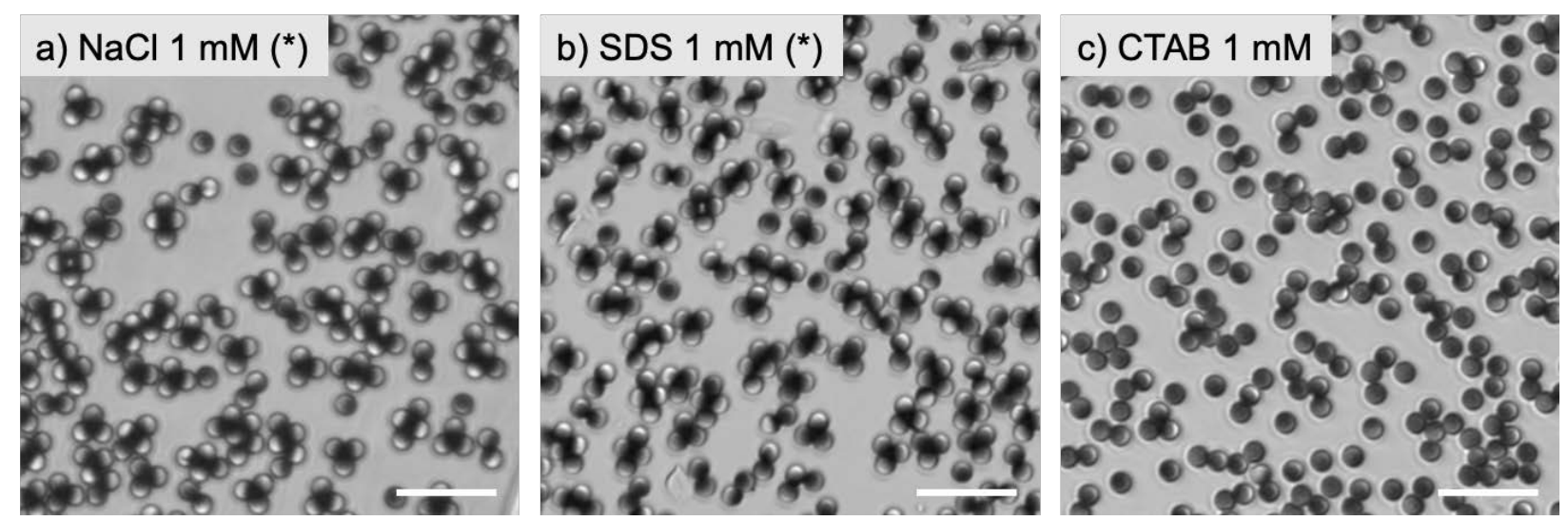

Figure S1. Optical images of ODT modified Janus particles assembled in $1 \mathrm{mM}$ aqueous solution of a) salt $\mathrm{NaCl}, \mathrm{b}$ ) anionic surfactant SDS, c) cationic surfactant CTAB, where $\left(^{*}\right)$ indicates that particles are mobile. Scale bar 15 um. 
Figure S2.

Spectra obtained by ${ }^{1} \mathrm{H}$ NMR of $\left[\mathrm{C}_{4} \mathrm{mim}^{+}\right]\left[\mathrm{Br}^{-}\right]$

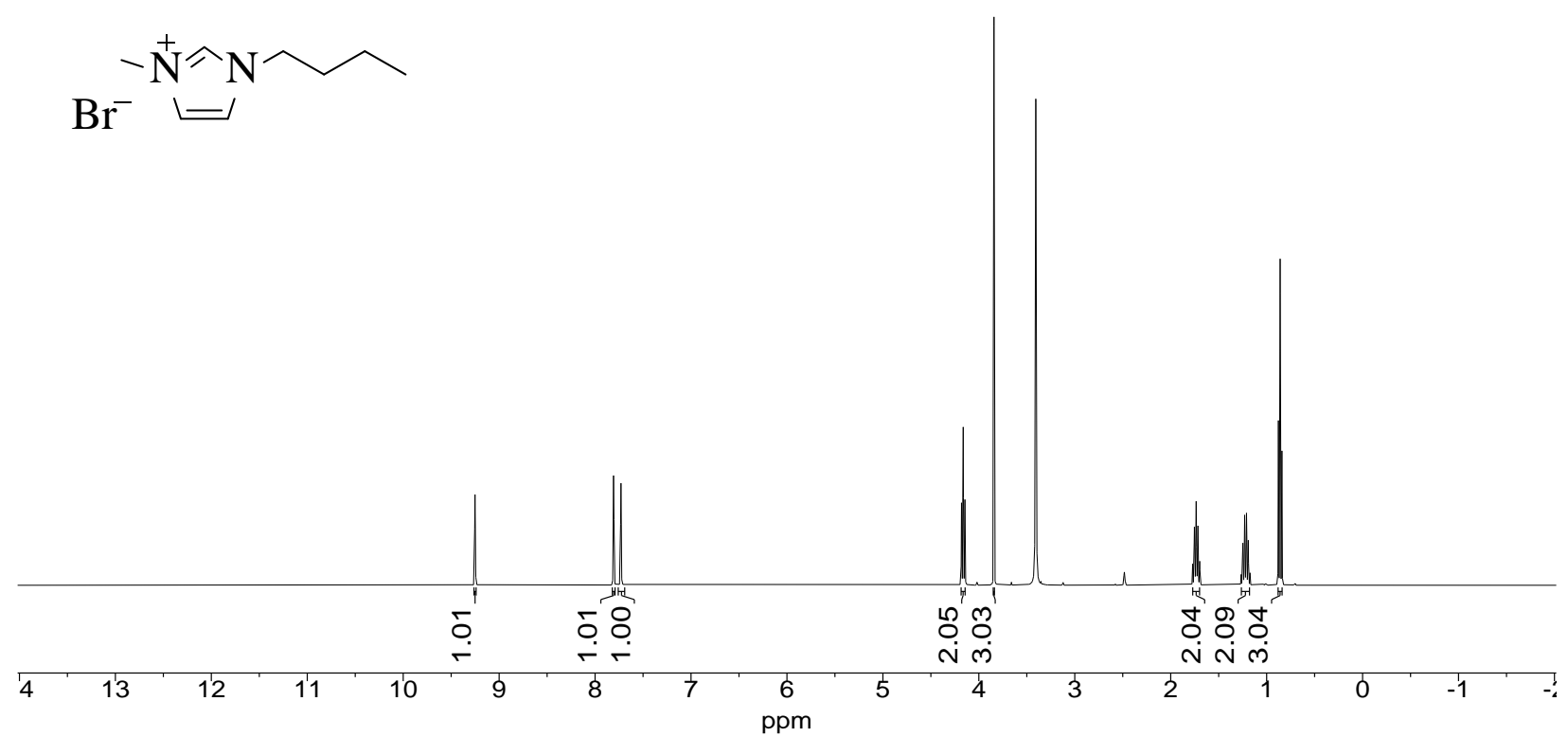

${ }^{1} \mathrm{H}$ NMR (400 MHz, DMSO- $\left.d_{6}, \mathrm{ppm}\right) \delta 9.25(\mathrm{t}, J=1.7 \mathrm{~Hz}, 1 \mathrm{H}), 7.81(\mathrm{t}, J=1.8 \mathrm{~Hz}, 1 \mathrm{H}), 7.73(\mathrm{t}$, $J=1.8 \mathrm{~Hz}, 1 \mathrm{H}), 4.16(\mathrm{t}, J=7.2 \mathrm{~Hz}, 2 \mathrm{H}), 3.84$ (s, 3H), $1.79-1.68$ (m, 2H), 1.21 (dt, $J=14.7,7.4$ $\mathrm{Hz}, 2 \mathrm{H}), 0.86$ (t, $J=7.4 \mathrm{~Hz}, 3 \mathrm{H})$. 
Spectra obtained by ${ }^{13} \mathrm{C}$ NMR of $\left[\mathrm{C}_{4} \mathrm{mim}^{+}\right]\left[\mathrm{Br}^{-}\right]$

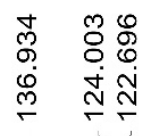

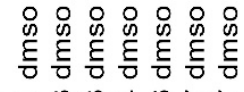

伭守

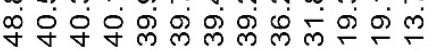

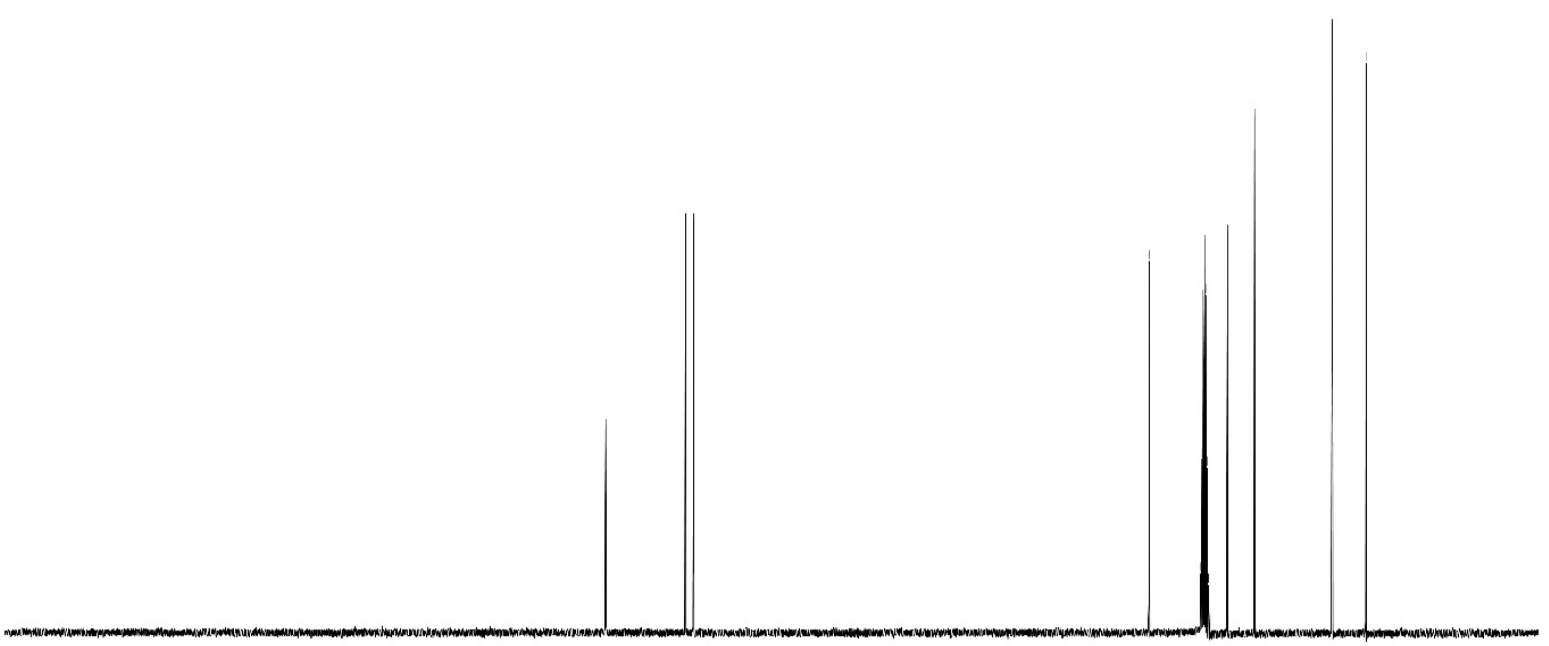

$\begin{array}{lllllllllllllllllllllllllllll}1 & 1 & 220 & 210 & 200 & 190 & 180 & 170 & 160 & 150 & 140 & 130 & 120 & 110 & 100 & 90 & 80 & 70 & 60 & 50 & 40 & 30 & 20 & 10 & 0 & -10\end{array}$ ppm

${ }^{13} \mathrm{C}$ NMR (101 MHz, DMSO-d 6 , ppm) $\delta 136.93,124.00,122.70,48.89,40.54,40.33,40.12,39.91$, 39.71, 39.50, 39.29, 36.22, 31.82, 19.37, 19.20, 13.74 . 
Spectra obtained by ${ }^{1} \mathrm{H}$ NMR of $\left[\mathrm{C}_{4} \mathrm{C}_{1} \mathrm{mim}^{+}\right]\left[\mathrm{Br}^{-}\right]$<smiles>CCCCn1cc[n+](C)c1C</smiles>

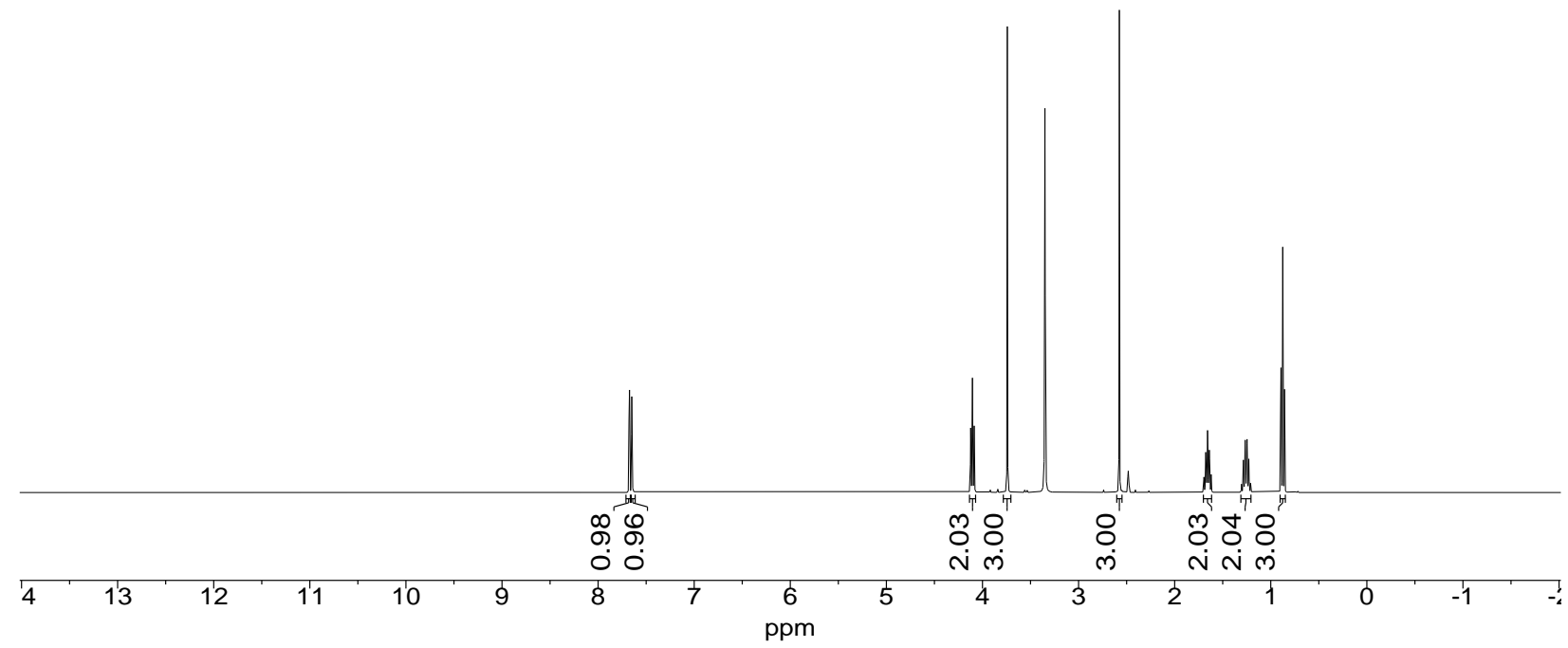

${ }^{1} \mathrm{H}$ NMR (400 MHz, DMSO- $d_{6}$, ppm) $\delta 7.70-7.62(\mathrm{~m}, 2 \mathrm{H}), 4.10$ (t, $\left.J=7.3 \mathrm{~Hz}, 2 \mathrm{H}\right), 3.74$ (s, 3H), 2.58 (s, 3H), $1.72-1.60$ (m, 2H), 1.26 (h, $J=7.4 \mathrm{~Hz}, 2 \mathrm{H}), 0.88$ (t, $J=7.4 \mathrm{~Hz}, 3 \mathrm{H})$. 
Spectra obtained by ${ }^{13} \mathrm{C}$ NMR of $\left[\mathrm{C}_{4} \mathrm{C}_{1} \mathrm{mim}^{+}\right]\left[\mathrm{Br}^{-}\right]$

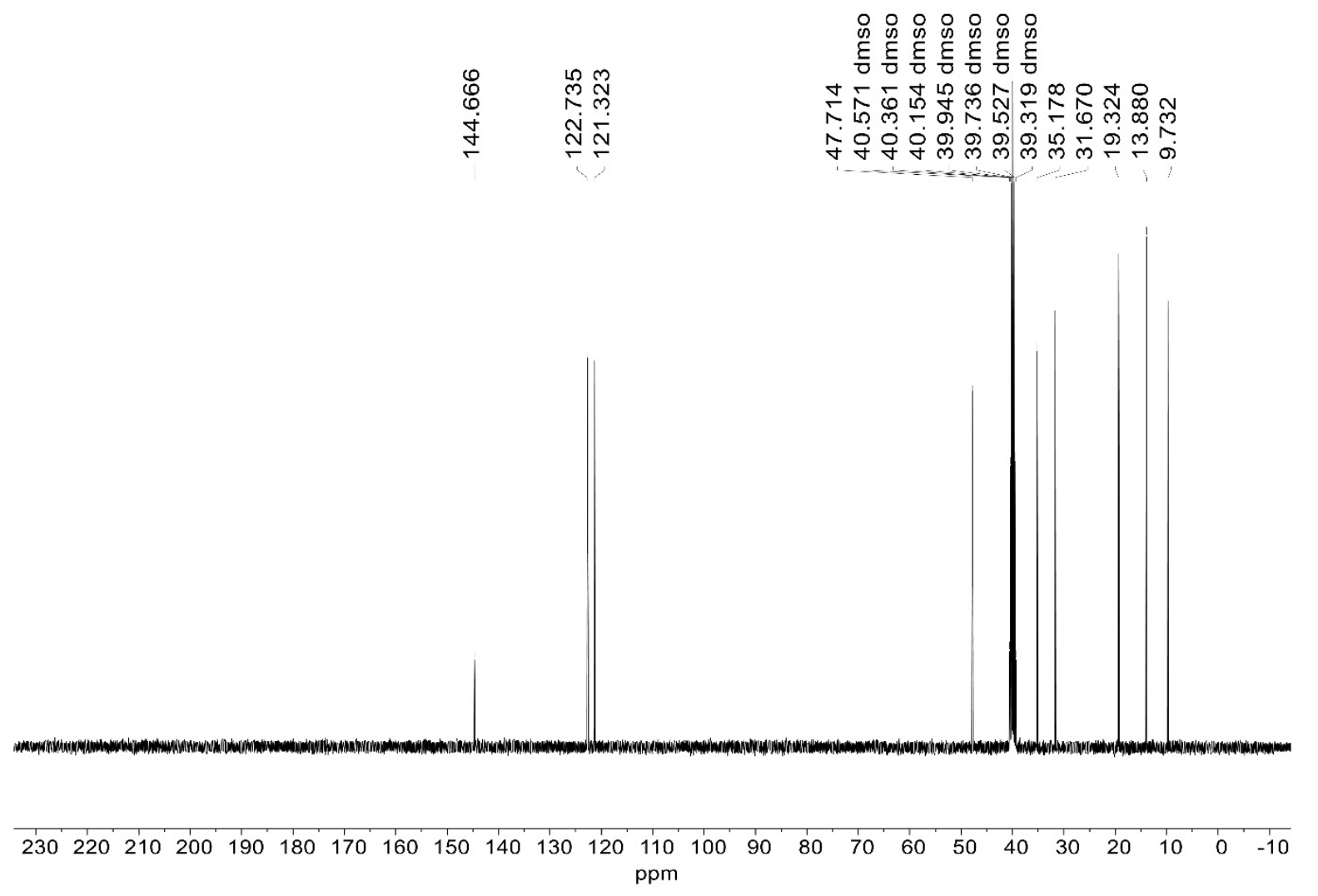

${ }^{13} \mathrm{C}$ NMR $\left(101 \mathrm{MHz}\right.$, DMSO- $d_{6}$, ppm) $\delta 144.67,122.73,121.32,47.71,40.57,40.36,40.15,39.94$, 39.74, 39.53, 39.32, 35.18, 31.67, 19.32, 13.88, 9.73. 
Spectra obtained by ${ }^{1} \mathrm{H}$ NMR of $\left[\mathrm{C}_{10} \mathrm{mim}^{+}\right]\left[\mathrm{Br}^{-}\right]$

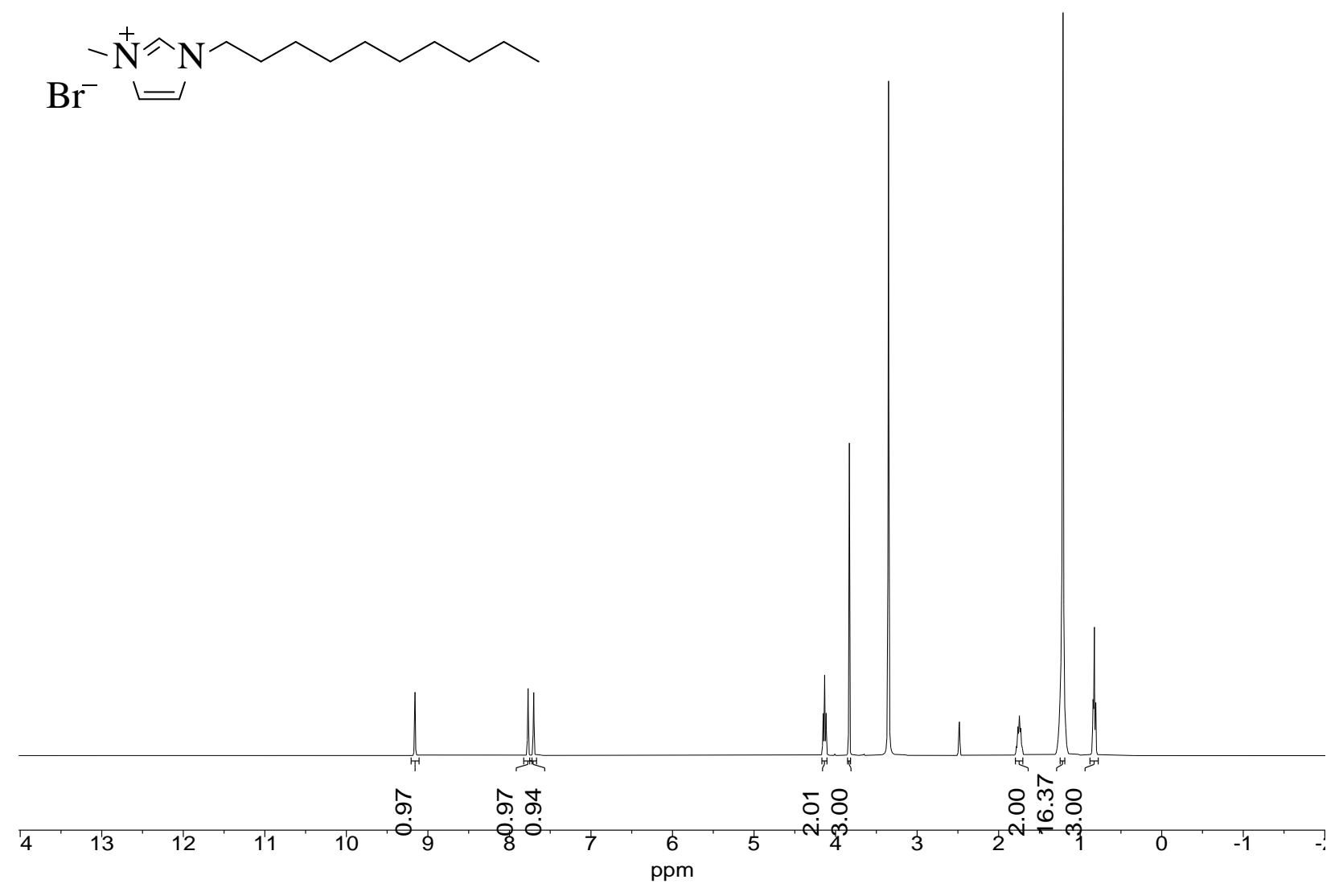

${ }^{1} \mathrm{H}$ NMR (400 MHz, DMSO- $d_{6}$, ppm) $\delta 9.16(\mathrm{~d}, J=2.3 \mathrm{~Hz}, 1 \mathrm{H}), 7.77$ (t, $\left.J=1.8 \mathrm{~Hz}, 1 \mathrm{H}\right), 7.70$ (d, $J=1.9 \mathrm{~Hz}, 1 \mathrm{H}), 4.13$ (t, $J=7.2 \mathrm{~Hz}, 2 \mathrm{H}), 3.83$ (d, $J=2.1 \mathrm{~Hz}, 3 \mathrm{H}), 1.75$ (p, $J=7.1 \mathrm{~Hz}, 2 \mathrm{H}$ ), 1.23 (d, $J=9.0 \mathrm{~Hz}, 4 \mathrm{H}), 1.21$ (s, 12H), $0.86-0.79$ (m, 3H). 
Spectra obtained by ${ }^{13} \mathrm{C}$ NMR of $\left[\mathrm{C}_{10} \mathrm{mim}^{+}\right]\left[\mathrm{Br}^{-}\right]$

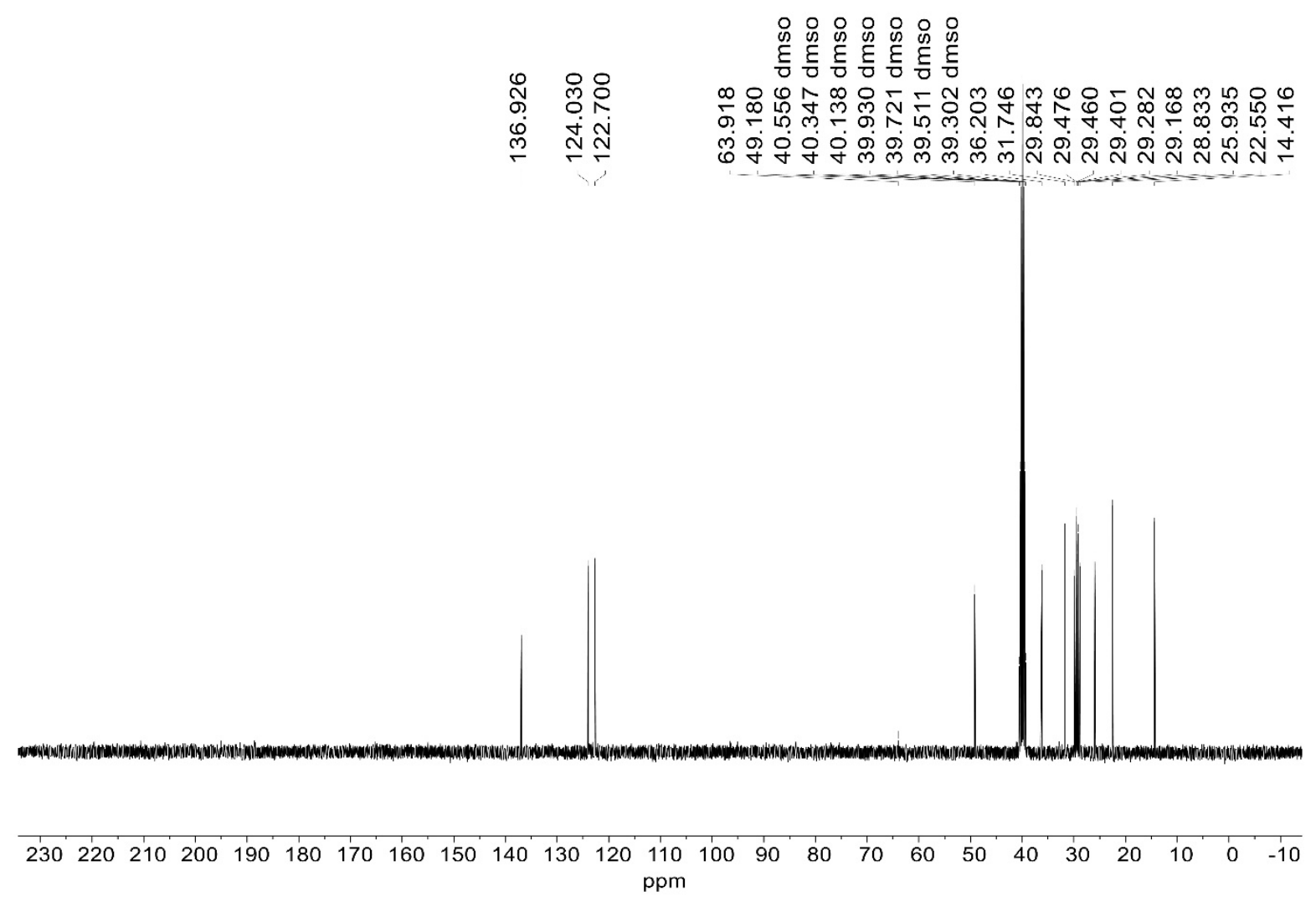

${ }^{13} \mathrm{C}$ NMR (101 MHz, DMSO- $d_{6}$, ppm) $\delta 136.93,124.03,122.70,63.92,49.18,40.56,40.35$, 40.14, 39.93, 39.72, 39.51, 39.30, 36.20, 31.75, 29.84, 29.48, 29.46, 29.40, 29.28, 29.17, 28.83, 25.94, 22.55, 14.42 . 

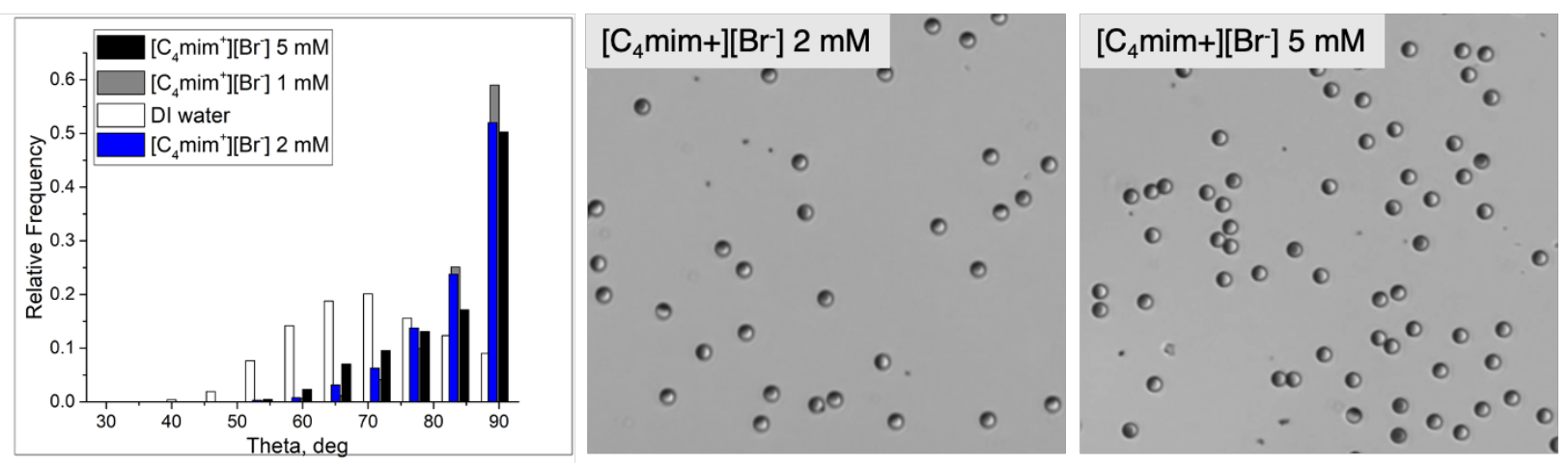

Figure S3. Orientation distribution of ODT Janus particles in aqueous solution of [C4mim+][Br-], and corresponding optical images of Janus spheres assembled in $2 \mathrm{mM}$ and $5 \mathrm{mM}$ of $\left[\mathrm{C}_{4} \mathrm{mim}^{+}\right]\left[\mathrm{Br}^{-}\right]$

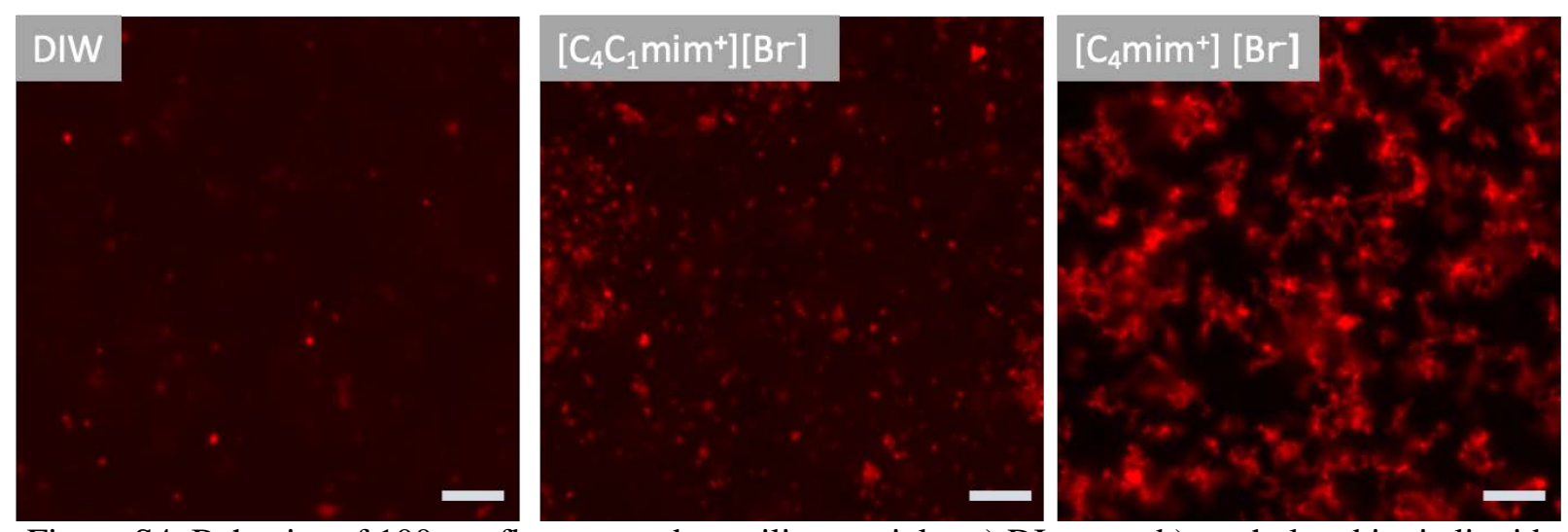

Figure S4. Behavior of $100 \mathrm{~nm}$ fluorescent bare silica particles a) DI water, b) methylated ionic liquid $\left[\mathrm{C}_{4} \mathrm{C}_{1} \mathrm{mim}^{+}\right]\left[\mathrm{Br}^{-}\right]$, and c) $\left[\mathrm{C}_{4} \mathrm{mim}^{+}\right]\left[\mathrm{Br}^{-}\right]$at $5 \mathrm{mM}$. Scale bar is $10 \mathrm{um}$.

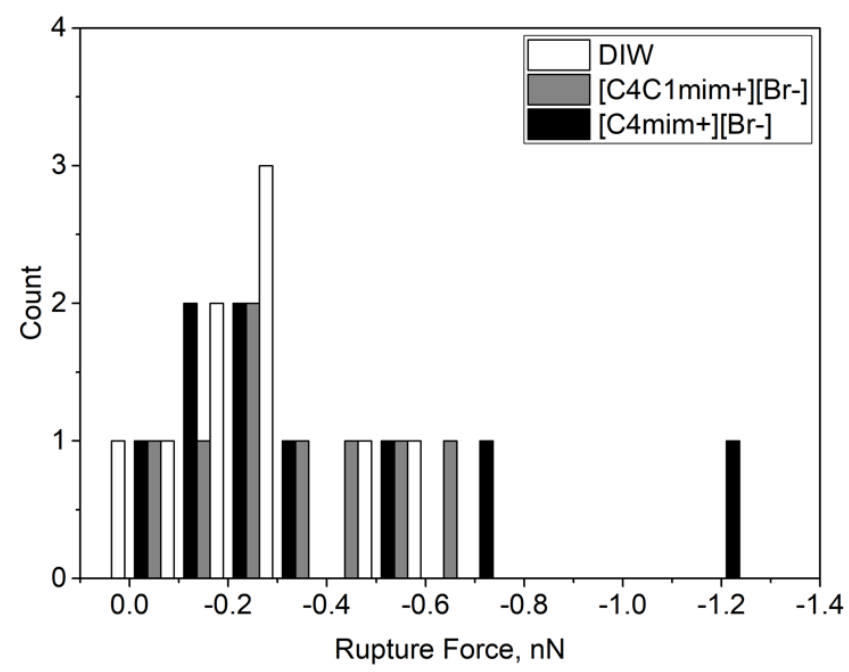

Figure S5. Distribution of rupture force between a colloidal 5 um silica probe and the glass substrate at different experimental conditions 